\title{
GRANULOMA PIOGÊNICO: RELATO DE CASO CLÍNICO-CIRÚRGICO
}

Rafael Martins VALÉRIO, Eduardo MORESCHI, Cristiane Yuri Kohiyama SCHUTZ, Newton Cesar KAMEI

O Granuloma Piogênico é uma lesão reativa comum, que se caracteriza por uma proliferação excessiva de tecido conjuntivo como resposta a uma agressão. Pode aparecer tanto em pele como em mucosas, sendo a boca o local mais afetado (CAPELARI et al., 2009). Na cavidade bucal, caracteriza-se clinicamente por crescimento tecidual exofítico, séssil ou pediculado, de coloração eritematosa à acastanhada, geralmente ulcerada e com sangramento espontâneo. A exérese cirúrgica da lesão, associada à remoção dos fatores irritativos locais, como as doenças periodontais, biofilme e cálculos dentários (REYES et al., 2008), representam o tratamento de escolha. $O$ seguinte trabalho tem o propósito de apresentar um caso clínico de paciente do gênero feminino, 46 anos, feoderma, encaminhada ao Serviço de Cirurgia do curso de Odontologia do Centro Universitário de Maringá, com a presença de uma extensa lesão na região posterior da maxila direita. Clinicamente, apresentava-se como uma massa nodular, de superfície moriforme, base pediculada, coloração avermelhada, revestida parcialmente por membrana amarelada, assintomática, medindo aproximadamente $16,0 \mathrm{~mm} \times 8,0 \mathrm{~mm}$. Ao exame radiográfico, observou-se presença de raízes residuais sob a lesão, corroborando com a hipótese de Granuloma Piogênico. O tratamento consistiuse na remoção total da lesão, e dos possíveis agentes causais, entre eles, as raízes residuais.

Palavras-chave: Estomatologia; Granuloma Piogênico; Patologia bucal. 